\title{
Can Estrogen Receptor, Progesterone Receptor, and Proliferative Index be Considered as Isolated Prognostic Factors of Overall Survival in Early luminal Breast Cancer?
}

\author{
Marija Karakolevska-Ilova ${ }^{1 *}$ (D), Milka Zdravkovska ${ }^{2}$, Dgengis Jasar $^{3}$, Gordana Petrusevska $^{4}$, Elena Simeonovska-Joveva ${ }^{5}$ \\ ${ }^{1}$ Departement of Oncology, Faculty of Medical Sciences, University Goce Delcev, Clinical Hospital Shtip, Shtip, Macedonia; \\ ${ }^{2}$ Faculty of Medical Sciences, University Goce Delcev, Shtip, Macedonia; ${ }^{3}$ Department of Pathology, Faculty of Medical Sciences, \\ University Goce Delcev Shtip, Clinical Hospital Acibadem-Sistina, Skopje, Macedonia; ${ }^{4}$ Institute of Pathology, University St. \\ Cyril and Methodius, Skopje, Macedonia; ${ }^{5}$ Departement of Neurology, Faculty of Medical Sciences, University Goce Delcev, \\ Clinical Hospital Shtip, Shtip, Macedonia
}

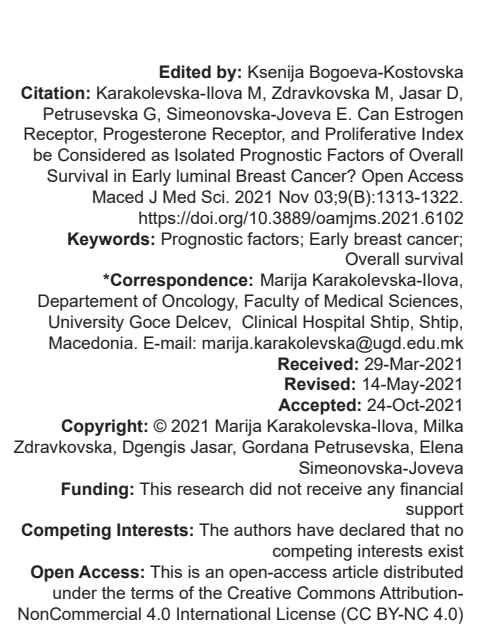

Abstract

BACKGROUND: There are a number of proven molecular and pathological markers important for the prognosis for OS of early luminal type breast cancer, but there are still some deficiencies mainly due to the non-linear relationship between the markers and the outcome of the disease.

METHODS AND PATIENTS: In this retro-prospective study, clinical and pathological data were provided from 336 patients with breast cancer who underwent breast surgery and treatment between January 2010 and December 2013, and followed until December 2018. The aim of the study was an evaluation of ER, PR, and Ki-67 as independent prognostic factors for OS of early luminal breast cancer.

RESULTS: Early luminal breast cancers were not predictive of ER expression status $(p=0.699, p=0.356)$, whereas only early Luminal B was predictive for PR expression (>10\%: $72.2 \%)$. Ki-67 in most of the cases of early Lumina $B$ was with expression of $>14-20 \%(p=0.056)$. Patients with ER of $1-10 \%$ survived over 80 months $(p=0.0020)$ in early Luminal A, but ER expression status did not show prognostic significance for OS of early Luminal $B(p=0.775)$ PR status did not show prognostic significance for OS in early luminal types $(p=0.257, p=0.622)$. ER $>1 \% / P R>1 \%$ was protective in early Luminal $B(p=0.00043)$, but not in early Luminal A.

CONCLUSION: Our results suggest ER, but not PR as independent prognostic factor for OS but only of early Luminal A. We did not prove Ki-67 as independent prognostic factor for OS of highly proliferative early breast cancer.

\section{Introduction}

Mortality from breast cancer is declining due to the possibility of early diagnosis and proper oncological treatment [1]. However, the dilemma remains for the therapy of early stage breast cancer, in terms of pretreatment/ subtreatment of patients as a result of underestimated predictions [2]. In each patient, breast cancer is presented with appropriate specific biological prognostic features.

The "St. Gallen International Expert Consensus" 2011 proposed a new classification system for breast cancer based on its division into five subgroups. The criteria to identify subtypes were further revised, and at the 2015 Conference the breast cancer was classified into five molecular types as: Luminal $A$ (estrogen receptor [ER]-positive/progesterone receptor [PR]-positive/negative, HER-2/neu negative, Ki-67 $<14 \%$ ); Luminal B/HER-2/neu negative (ER-positive/ PR-positive/negative, HER-2/neu negative, Ki-67 $\geq 14 \%$ ); Luminal B/HER-2/neu positive (ER-positive/ PR-positive/negative, HER-2/neu negative, Ki-67 any value); HER-2/neu positive (ER-positive/PR-positive/ negative, HER-2/neu positive, Ki-67 any value); and Triple negative (ER-negative/PR-negative, HER-2/ neu negative, Ki-67 any value), which have different treatment and different prognosis in terms of diseasefree survival (DFS) and overall survival (OS) [3].

The most dominant biological type of breast cancer is Luminal A $(51.6 \%)$, followed by the triple negative biological type (32.1\%). Luminal $\mathrm{B}$ has a prevalence of $10.1 \%$, while non-luminal HER-2/neu positive with $6.3 \%$ [4].

Hormone receptor (HR) positive breast cancers (Luminal breast cancers: Luminal A and Luminal B) account for $2 / 3$ of all biological types of breast cancer. Luminal breast cancers are highly heterogeneous, involving different histological types, different gene expression profiles and mutation frames, with different clinical presentations, and outcome of appropriate 
therapy. Although they belong to the group of biological types with low aggressiveness, despite the applied hormone and chemotherapy, occasionally have very aggressive clinical features.

Most studies showed that Luminal B type differs greatly from Luminal A type, and at "The 2013 International Expert Consensus on Primary Therapy for Early Breast Cancer" (St. Gallen) Luminal $A$ was distinguished from Luminal $B$ based on immunohistochemical (IHC) assays for ER, PR, and Ki-67 status without molecular testing [5], [6].

There are a number of proven molecular and pathological markers important for the prognosis of breast cancer, including early stage luminal type, but there are still some deficiencies in terms of treatment prediction and prognosis [7]. This is mainly due to the non-linear relationship between the markers and the outcome of the disease, which is an incentive for clinicians to accurately predict the prognosis based on these markers. Therefore, the need for accurate statistics in this context is more than necessary.

Some of the studies showed that the most relevant factors for prognostic and for predicting are the combination of tumor size (T), PR status, and p53 gene protein product [7], [8]. ER and PR are prognostic factors, although both are weak and lose their prognostic value after a long follow-up period [9], [10]. "St. Gallen Expert Consensus" from 2015 emphasized the PR expression which together with proliferative index $\mathrm{Ki}-67$ determines the heterogeneity of luminal types of breast cancer which results in their increased aggressiveness in certain cases [3].

High Ki-67 values correlate with negative ER and $\mathrm{PR}$, worse prognosis and early relapse (within 2 years), as opposed to the low $\mathrm{Ki}-67$ values which correlate with a better prognosis and later relapse (after 10 years) [11]. Therefore, the proliferative activity determined by $\mathrm{Ki}-67$ reflects the aggressive course of breast cancer and is a predictive factor for the time of relapse and the application of appropriate therapy, so it is considered an important prognostic factor in survival prediction [12], [13].

To enable a correct assessment of relapse risk and $\mathrm{OS}$ in early luminal breast cancer, it is necessary to consider all factors, especially in T2 tumors. In the study of Park et al., 183 patients with Luminal B/ HER-2/neu negative breast cancer were divided into two groups: ER and PR positive versus ER or PR negative, and $\mathrm{Ki}-67>14 \%$. Both groups were followed for DFS and OS, in correlation with age, type of surgery, histological type, TNM stage, histological grade and $\mathrm{Ki}-67$, to determine the association between the degree of $\mathrm{Ki}-67$ proliferation and the degree of expression of ER/PR as predictive and prognostic factors. The study showed a statistically significant difference in the degree of PR expression and the DFS period and OS with linear dependence $(p<0.0001)$ [5]. Negative
$\mathrm{PR}$ in luminal types of breast cancer predicts worse survival [14], but its prognostic value across groups is still a subject of numerous studies, starting from the fact that low-proliferative tumors with a negative PR are also classified as high risk. Despite negative studies on the association of PR and tumor grade as prognostic markers, PR negative tumors show a higher incidence of relapses in highly proliferative than in low proliferative luminal tumors.

Pérez-López et al. analyzed the effect of Ki-67 as a prognostic marker of early node negative Luminal $B$ breast cancer and concluded that it affects survival, but progesterone status did not show prognostic value [15]. In contrast, the study of Ono et al. showed that progesterone status affects survival and the recurrence of local relapse and distant metastases, especially in the Luminal A biological type (Ki-67<14\%), but the limiting factor of the study was the small study group of 49 patients [16].

Taking into account all previous studies and recommendations, the prognostic value of $\mathrm{Ki}-67$, the degree of ER and PR expression, in early Luminal A and $\mathrm{B}$ breast remains undefined completely.

\section{Material and Methods}

In this retro-prospective study, clinical and pathological data were provided from 336 patients with breast cancer who underwent breast surgery and treatment between January 2010 and December 2013. Follow-up was provided until December 2018.

The data of each patient for diagnostic procedures, surgical interventions, therapeutic procedures (including all specific oncological treatments) and follow-up protocols, were obtained through the patient's electronic documentation within the National Electronic Records System in healthcare of RNMacedonia. The data from the pathological analysis of the surgical specimen from the patients, as well as for performed immunohistochemistry, were obtained from the patients' database of pathohistological-cytological laboratory in the Clinical Hospital - Sistina, Skopje.

The patients included in the study were women (from 30 up to 80-years-old, regardless of menopausal status), with early and advanced breast cancer, who underwent radical mastectomy or quadrantectomy with axillary lymph node dissection, regardless of the adjuvant treatment: Chemotherapy, hormonotherapy, or both. The breast cancer was classified in biological subtypes according to the criteria of St. Gallen from 2015 [3], and in pathohistological types according to the World Health Organization [17]. The stage of the disease was determined according to the TNM classification of breast cancer [18]. 
Patients treated with neoadjuvant chemotherapy and male patients with breast cancer were excluded.

The HR status (ER and PR) as well as proliferative index expression $\mathrm{Ki}-67$ and expression of HER-2/neu were analyzed from immunohistochemical (IHC) reports for formalin-fixed, paraffin-embedded tumor tissue according to international standards. During the IHC analyzing of the slides from surgical specimen, using positive and negative control for the estrogen and PR, as well as for the proliferative marker $\mathrm{Ki}-67$, DacoCytomation antibodies were used, as well as the DacoCytomation EnVision + System - HRP imaging system, and the HercepTest DacoCytomation kit was used for the herceptin test.

The results for ER and PR were evaluated as the percentage of stained nuclei (1-100\%), with $<1 \%$ - no expression, $1-10 \%$ weakly positive, and $>$ $10 \%$ - strongly positive nuclear staining [19].

Immunoreactivity for $\mathrm{Ki}-67$ was evaluated as the percentage of stained nuclei $(0-100 \%)$, whereby patients in terms of its expression were divided into groups where Ki-67 <14\% (Luminal A type - [0-14\%]), $\geq 14 \%$ (Luminal B type), with subgroups ( $\geq 14-20 \%$, $>20-30 \%,>30-40 \%$, and $>40 \%$ ).

The data were processed for early stage (T0/T1/T2, N0/N1 [1-3 positive lymph nodes]) Luminal $A$ and Luminal B breast cancer.

The aim of this study was to determine the prevalence of luminal breast cancer and early luminal breast cancer, evaluation of OS for early luminal breast cancer and evaluation of ER, PR, and Ki-67 as independent prognostic factors for OS of early luminal breast cancer.

OS survival was defined as the time until the last examination of the patient or until the occurrence of death from any cause.

Chi-square exact test was used to compare discrete variables. OS was assessed using Kaplan-Meier method, and long-rank tests were used to compare the differences between the resulting curves. Hazard ratios, 95\% confidence intervals $(\mathrm{Cl})$ were performed using Cox proportional - hazard model to evaluate prognostic significance of each parameter in patients with early luminal breast cancer. In all analyses, differences were considered significant if $p<0.05$.

\section{Results}

Among 336 patients with breast cancer, Luminal B biological type was registered in more than a half $(59.5 \%)$ of the patients, whereas Luminal $A$ was registered in $16.1 \%$ of the patients, followed by HER2 positive (14.6\%) and Triple negative breast cancer $(9.8 \%)$ (Table S1). The difference in prevalence between Luminal $B$ and other biological types was statistically significant $(p<0.05)$.

Early Luminal A and Luminal B accounted with $49.7 \%$ of the total number of patients diagnosed with luminal breast cancer. There was a statistically significant difference between the prevalence of early and advanced Luminal A and Luminal B breast cancer $(p<0.05)$ (Table S2). Additional analysis showed a significant association of luminal biological types of their presentation with early stage $(p=0.0001)$ (Table S2).

The prevalence of biological types of breast cancer from IHC findings (Table S1) as well prevalence of Luminal A and Luminal B/early and advanced breast (Table S2) cancer can be found in the supplementary tables.

Early luminal breast cancer was with positive ER expression (>10\%) in $93.4 \%$ of the cases, with low positive ER expression in $5.4 \%$ of the cases and only $1.2 \%$ of the cases were without ER expression.

Low positive ER expression was found in two cases, while ER expression $>10 \%$ in $95.1 \%$ of the cases with early Luminal A type, but there was no statistically significant correlation between ER expression and early Luminal A ( $p>0.05$, Pearson Chi-square: 0.148990, df $=1, p=0.699502)$. In early Luminal B breast cancer there was no ER expression in two patients, while positive and low positive ER expression was found in $92.9 \%$ and $5.6 \%$ of the cases respectively, but that was without statistical significance. $(p>0.05$, Pearson Chi-square: 2.06392, df $=2, p=0.356308$ ) (Table 1).

Table 1: ER and PR expression in patients with early Luminal A $(\mathrm{N}=41)$ and Luminal $\mathrm{B}(\mathrm{N}=167)$ breast cancer

\begin{tabular}{lllllllll}
\hline & \multicolumn{2}{l}{ No expression } & \multicolumn{2}{l}{ Low positive } & \multicolumn{2}{l}{ Positive } & \multicolumn{3}{l}{ Total } \\
\hline ER expression (\% ) & $\mathrm{N}$ & $\%$ & $\mathrm{~N}$ & $\%$ & $\mathrm{~N}$ & $\%$ & $\mathrm{~N}$ & $\%$ \\
\hline Early Luminal A & 0 & & 2 & $4.9 \%$ & 39 & $95.1 \%$ & 41 & $100.0 \%$ \\
Early Luminal B & 2 & $1.6 \%$ & 7 & $5.6 \%$ & 117 & $92.9 \%$ & 126 & $100.0 \%$ \\
Early Luminal A+B & 2 & $1.2 \%$ & 9 & $5.4 \%$ & 156 & $93.4 \%$ & 167 & $100.0 \%$ \\
\hline PR expression (\% ) & $\mathrm{N}$ & $\%$ & $\mathrm{~N}$ & $\%$ & $\mathrm{~N}$ & $\%$ & $\mathrm{~N}$ & $\%$ \\
\hline Early Luminal A & 3 & $7.3 \%$ & 5 & $12.2 \%$ & 33 & $80.5 \%$ & 41 & $100.0 \%$ \\
Early Luminal B & 27 & $21.4 \%$ & 8 & $6.3 \%$ & 91 & $72.2 \%$ & 126 & $100.0 \%$ \\
Early Luminal A+B & 30 & $18 \%$ & 13 & $7.8 \%$ & 124 & $74.2 \%$ & 167 & $100.0 \%$ \\
\hline
\end{tabular}

PR expression $>10 \%$ was found in $74.2 \%$ of patients with early luminal breast cancer, while low positive expression in $7.8 \%$. PR had no expression in $18 \%$ of the luminal types.

There was no PR expression in three patients with early Luminal A breast cancer, positive and low positive PR expression was in $80.5 \%$ and $12.2 \%$, respectively, but the difference was not statistically significant ( $p>0.05$, Pearson Chi-square: 2.54731, df $=2, p=0.279808$ ). PR expression $>10 \%$ was found in $72.2 \%$ of the patients with early Luminal $B$ and there was no PR expression in $21.4 \%$ of the patients with statistically significant difference $(p<0.05$, Pearson Chi-square: 8.63828, df $=2, p=0.013311$ ) (Table 1).

In most of the patients with early Luminal $B$ breast cancer $(42.8 \%)$, the proliferative index Ki-67 was with expression of $\geq 14-20 \%$, while the expression 
Table 2: Ki-67 expression in early Luminal A and Luminal B breast cancer

\begin{tabular}{|c|c|c|c|c|c|c|c|c|c|c|c|c|}
\hline \multirow[t]{3}{*}{ Cancer type } & \multicolumn{12}{|c|}{ Parametar Ki-67\% } \\
\hline & \multicolumn{2}{|c|}{$<14 \%$} & \multicolumn{2}{|c|}{$\geq 14-20 \%$} & \multicolumn{2}{|c|}{$>20-30 \%$} & \multicolumn{2}{|c|}{$>30-40 \%$} & \multicolumn{2}{|c|}{$>40 \%$} & \multirow{2}{*}{\multicolumn{2}{|c|}{$\begin{array}{l}\text { Total } \\
\mathrm{N}\end{array}$}} \\
\hline & $\mathrm{N}$ & $\%$ & $\mathrm{~N}$ & $\%$ & $\mathrm{~N}$ & $\%$ & $\mathrm{~N}$ & $\%$ & $\mathrm{~N}$ & $\%$ & & \\
\hline Early LuminalA/Ki-67\% & 41 & $100 \%$ & 0 & $0 \%$ & 0 & $0 \%$ & 0 & $0 \%$ & 0 & $0 \%$ & 41 & $n=0,0561$ \\
\hline Early LuminalB/Ki-67\% & 0 & $0 \%$ & 54 & $42.8 \%$ & 43 & $34.1 \%$ & 19 & $15.1 \%$ & 10 & $7.9 \%$ & 126 & \\
\hline Early LA+LB/Ki- $67 \%$ & 41 & $24.5 \%$ & 54 & $32.3 \%$ & 43 & $25.7 \%$ & 19 & $11.4 \%$ & 10 & $6.0 \%$ & 167 & \\
\hline
\end{tabular}

$>40 \%$ was found in $7.9 \%$ of the patients. There was no statistically significant difference of the expression of proliferative index Ki-67 in early Luminal B breast cancer. $(p>0.05$, Pearson Chi-square: 7.55504, $d f=3$, $\mathrm{p}=0.056161)$ (Table 2).

Kaplan-Meier survival curves for OS of 254 patients stratified according to Luminal Aand Luminal $B$ breast cancer can be found in the supplementary Figure S1. There was statistically significant difference of OS between early and advanced Luminal $A$ and Luminal B breast cancer $(p<0.05$, Pearson Chi-square: 20.23704, $\mathrm{df}=3, \mathrm{p}=0.00015)$ (Figure S1).

Two of the patients $(5.26 \%)$ with early Luminal A breast cancer died during the evaluation period, while seven of the patients $(5.56 \%)$ with early Luminal B.

There was a statistically significant difference for OS of patients with early Luminal A breast cancer with different ER expression statuses. Long Rank test (Mantel-Cox-Chi-square) (WW $=0.92593$, Sum $=1.8519$, Var $=0.09483$, Test statistic $=3.006765, p=0.00209$ ) . Namely, $98 \%$ of the patients with ER expression $>10 \%$ survived over 80 months, while no one of the patients with ER expression of 1-10\% (Figure 1).

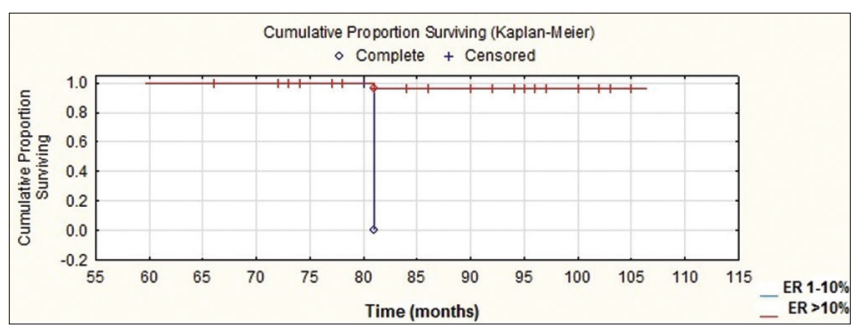

Figure 1: Survival curves for overall survival rate of patients with early Luminal A breast cancer according to ER expression status

There were no statistically significant differences for OS of patients with different ER expression of early Luminal B breast cancer. (Chisquare test $=0.5091705, d f=2, p=0.77524)($ Figure 2$)$.

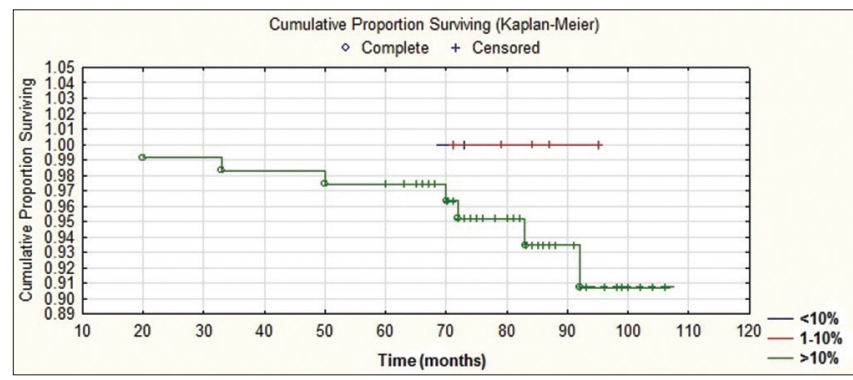

Figure 2: Survival curves for overall survival of patients with early Luminal B breast cancer according to ER expression status

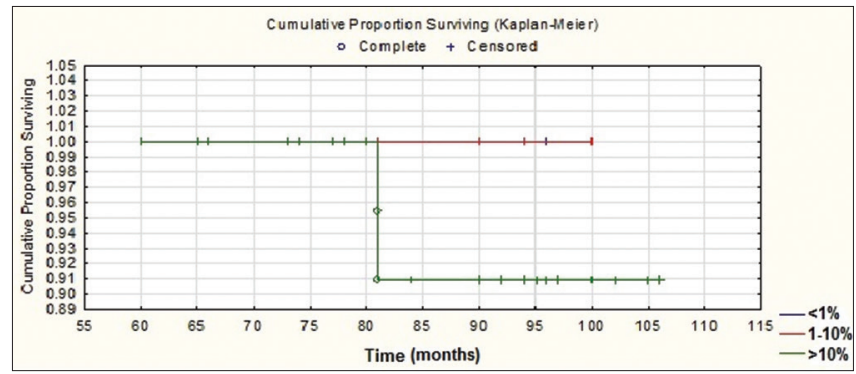

Figure 3: Survival curves for overall survival of patients with early Luminal A breast cancer according to PR expression status

Therewere nostatisticallysignificantdifferences for OS of patients with different PR expression of early Luminal A breast cancer. (Chi-square test $=0.9466090$, $\mathrm{df}=2, \mathrm{p}=0.62294)($ Figure 3$)$.

Therewere nostatistically significantdifferences for OS of patients with different PR expression of early Luminal B breast cancer. (Chi-square test $=2.714381$, $\mathrm{df}=2, \mathrm{p}=0.25740)($ Figure 4).

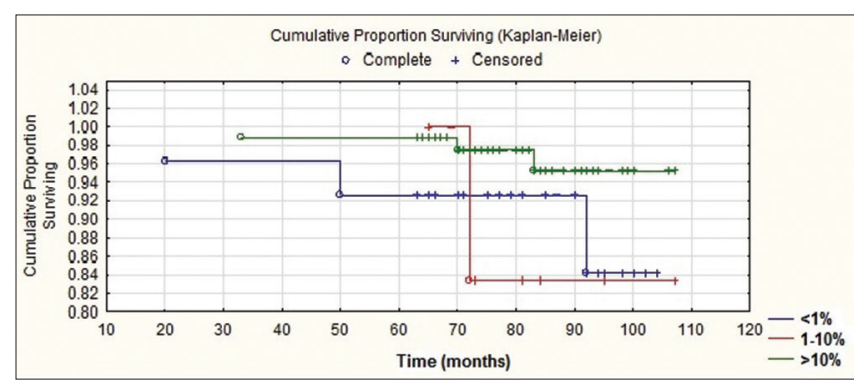

Figure 4: Survival curves for overall survival of patients with early Luminal B breast cancer according to PR expression status

Early Luminal A breast cancer was with ER $>1 \% / P R>1 \%$ in most of the cases $(92.7 \%)$, while only three patients had ER>1\%/PR $<1 \%$. Early Luminal $B$ breast cancer was also with $E R>1 \% / P R>1 \%$ in most of the cases $(77 \%)$ and $E R>1 \% / P R<1 \%$ was in $21.4 \%$. There were two patients with $\mathrm{ER}<1 \% / \mathrm{PR}>1 \%$. Survival curves for OS of patients with early Luminal A (Figure S2) and Luminal B breast cancer with ER $>1 \%$ / $\mathrm{PR}>1 \%$ (Figure S3) can be found in supplementary figures.

OS of patients with ER $>1 \% / P R>1 \%$ early Luminal A breast cancer was over 100 months in $92.5 \%$ of cases, while with advanced stage was $80 \%$, but the difference was not statistically significant $p>0.05$ LogRank Test (Mantel-Cox-Chi-square) (WW $=-1.028$ Sum $=3.7278$ Var $=0.627913$, Test statistic $=-1.2974$ $\mathrm{p}=0.19462)$ (Figure S2). 
OS of patients with $E R>1 \% / P R>1 \%$ early Luminal B breast cancer was over 100 months in $94 \%$ of cases, while with advanced stage was $75 \%$. There was a statistically significant difference for OS between stages of Luminal B breast cancer. $p<0.05$ LogRank Test (Mantel-Cox-Chi-square) (WW $=-7.311,2$ Sum $=17.840$, Var $=4.3126$, Test statistic $=-3.52071$, $p=0.00043$ ). (Figure S3).

Survival curves for OS of patients with early Luminal B breast cancer with ER $>1 \% / P R<1 \%$ (Figure S4) as well comparison of OS curves between ER>1\%/ $\mathrm{PR}>1 \%$ and $\mathrm{ER}>1 \% / \mathrm{PR}<1 \%$ early Luminal $\mathrm{B}$ breast cancer (Figure S5) can be found in the supplementary figures.

OS of patients with $E R>1 \% / P R<1 \%$ early Luminal B breast cancer was over 100 months in $84.9 \%$ of cases, while with advanced stage was $75 \%$, but the difference was not statistically significant $p>0.05$ Log-Rank Test (MantelCox-Chi-square) $(\mathrm{WW}=-1.053$, Sum $=4.7971 \mathrm{Var}=$ 0.87074 , Test statistic $=-1.12865 p=0.25905)($ Figure S4).

OS of patients with early Luminal B breast cancer was over 100 months in $95.8 \%$ of cases compare to $82.5 \%$ of cases with $\mathrm{ER}>1 \% / \mathrm{PR}>1 \%$ and $\mathrm{ER}>1 \% /$ $\mathrm{PR}<1 \%$, respectively, but the difference was not statistically significant. $p>0.05$ Log-Rank Test (MantelCox-Chi-square) $(\mathrm{WW}=-1.331$, Sum $=74.8995$, Var $=1.2586$, Test statistic $=-1.18657, p=0.23540$ ) (Figure S5).

There was no statistically significant difference for OS of patients of early Luminal B breast cancer according to different subgroup for expression of $\mathrm{Ki}-67 \%$. (Chi-square test $=3.132590$, df $=3$, $p=0.37165)($ Figure 5).

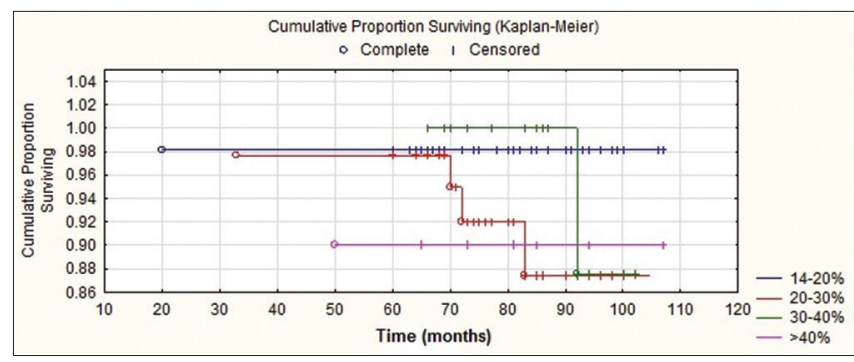

Figure 5: Survival curves for overall survival of in patients with early Luminal B breast cancer according to proliferative index Ki-67\%

Tables 3 and 4 report univariate analyses of the impact of ER, PR, and Ki-67 expression for OS.

Table 3: Univariate Cox regression analyses for OS of early Luminal A breast cancer

\begin{tabular}{lll}
\hline & $p$ value & $95 \% \mathrm{Cl} \operatorname{Exp}(\mathrm{B})$ \\
\hline ER expression & 0.018 & $0.010(0.000-0.529)$ \\
ER $1-10 \%$ v.s $>10 \%$ & & $0.032(0.000-26101.043)$ \\
PR expression & 0.619 & \\
PR $>1 \%$ v.s $<1 \%$ & &
\end{tabular}

In Cox univariate analysis for OS of patients with early Luminal A breast cancer, only low positive ER expression was associated with prolongation of OS. $\operatorname{Exp}(B)$ (HR) 0.010 (Table 3).
In Cox univariate analysis of OS for patients with early Luminal B breast cancer, no factor had any prognostic significance (Table 4).

\section{Discussion}

ER, PR, Ki-67, and HER 2/neu are conventional biomarkers that are useful in everyday practice to define a surrogate intrinsic subtype of breast cancer if genomic tests are not available, and estimate prognosis and predict adjuvant treatment decisions in early breast cancer [20]. Luminal A is shown to express high levels of HRs and a favorable prognosis, in contrast Luminal $B$ subtype is with worse prognosis.

Analyzing the results from 336 patients with breast cancer, classified in biological types based on findings from IHC of surgical specimens, our results showed that luminal breast cancers are the most dominant biological types $(75.6 \%, p<0.05)$, with Luminal B (43.4\%) as dominant subtype, also confirmed by other studies [21], [22], contrary to the studies that presented Luminal $\mathrm{A}$ as the most common biological type (50.9\%) [23]. All of these studies including ours, as a cross-sectional value for Ki-67 took the value of $<14 \%$, and thus the distinction between luminal types.

Table 4: Univariate Cox regression analyses for OS of early Luminal B breast cancer

\begin{tabular}{lll}
\hline & $p$ value & $95 \% \mathrm{Cl} \operatorname{Exp}(\mathrm{B})$ \\
\hline ER expression & 0.063 & $0.04928(0.000-1.7577)$ \\
$\begin{array}{l}\text { ER }<1 \% \text { v.s ER }>1 \% \\
\text { PR expression }\end{array}$ & & \\
PR $<1 \%$ v.s PR>1\% & 0.086 & $2.669(1.440-16.184)$ \\
ER $>1 \% / P R>1 \%$ v.s & & \\
ER $>1 \% / P R<1 \%$ & 0.293 & $0.381(0.063-2.3060)$ \\
Ki- $67 \%$ & & \\
$14 \%-20 \%$ & 0.962 & \\
$20 \%-30 \%$ & 0.953 & $0.000(0.000-2.5872+177)$ \\
$30 \%-40 \%$ v.s $>40 \%$ & 0.724 & $0.664(0.069-6.409)$ \\
\hline
\end{tabular}

Analysis showed a significant association of luminal biological types (Luminal A - 75.9\% and Luminal $B-63 \%)$ with early stage presentation $(49.7 \%)(p=0.0001)$.

To provide information about the prognostic significance of HRs in early luminal breast cancer for OS, we analyzed ER and PR expression status. Early luminal breast cancer in most of the patients $(93.4 \%)$ showed ER expression $>10 \%$, still when we analyzed ER expression status in early Luminal A ( $p=0.699502)$ and early Luminal $B(p=0.356308)$ separately, no one was predictive for the degree of ER expression. PR in $74.2 \%$ of the patients with early luminal types was $>10 \%$, and without $(<1 \%)$ expression in $18 \%$ of the cases. Only early Luminal B breast cancer showed to be predictive for PR expression, namely, early Luminal B breast cancer tent to be with PR expression $>10 \%(72.2 \%)$, but also PR was with no expression in $21.4 \%$ of the cases. $(p=0.013311)$ Our research is in contrast to the study of Prat et al. which showed that PR positivity, especially high PR expression, is more common in tumors with a 
better baseline prognosis, Luminal A than in tumors with a worse baseline prognosis, Luminal B [24].

We did not show the predictive value of early luminal types for ER expression, still early Luminal B was predictive for positive PR's expression.

A meta-analysis involving 12155 patients demonstrated that the Ki-67 positivity confers a high risk of recurrence and a worse survival rate in patients with early breast cancer, although it could not confirm that $\mathrm{Ki}-67$ had independent prognostic value beyond the standard clinic-pathological variables [12]. Another meta-analysis included 32825 patients with early breast cancer concluded that Ki-67 was associated with worse survival rates according of its proliferative status [25]. There are studies that confirmed the prognostic value of $\mathrm{Ki}-67$, but clinical validation is still a problem [26].

We used St. Gallen 2013 cutoff for Ki-67 in distinguishing Luminal $A$ from Luminal $B$, and evaluated the expression of $\mathrm{Ki}-67$ in early Luminal $\mathrm{B}$ where the $\mathrm{Ki}-67$ values were categorized into four categories ( $\geq 14-20 \%,>20-30 \%,>30-40 \%$, and $>40 \%$ ). The results did not show statistically significant difference between categories of Ki-67's expression ( $p=0.056161)$.

We did not show the predictive value of early Luminal $\mathrm{B}$ breast cancer for the expression of proliferative index Ki-67.

To investigate ER and PR's prognostic significance in early luminal types, we examined the survival curves for patients stratified according to $\mathrm{HR}$ expression (<1\%, $1-10 \%,>10 \%)$.

When we evaluated the impact of ER expression for OS of early Luminal A breast cancer patients, no one of the patients with low positive ER expression survived over 80 months (Long Rank test $p=0.0020$ ), which suggests that ER expression status was a prognostic factor for OS of early Luminal A breast cancer.

Analyzing survival curves for OS of early Luminal B breast cancer (126 patients), we found clinically interesting results, namely OS of the patients with ER expression $>10 \%$ after 70 months was declining gradually, but all of the patients with no or low ER expression survived longer (over 100 months). These results were not statistically significant $(p=0.77524)$, so ER expression status did not show its prognostic significance for OS of early Luminal B type.

PR expression and $\mathrm{Ki}-67$ using $\mathrm{IHC}$ are important prognostic factors in ER-positive early luminal breast cancers, which suggests PR's utility as a marker for differentiation between Luminal $A$ and Luminal B subtypes [24]. The studies showed that lack of PR expression is significantly associated with poorer prognosis in luminal breast cancers [27], independently of other factors [28], and PR-positive breast cancer had a better prognosis with regard to OS and DFS [24].

In study of Bracvaccini et al. only PR status in early luminal breast cancer was associated with OS and DFS among biological features. Namely, when the cutoff of PR was either $<10 \%$ or $<20 \%$ the patients had 5- and 10 -years OS rates of $92 \%$ and $80 \%$, respectively, compared with $95 \%$ and $89 \%$ for PR $>10 \%$ [27]. Another study showed that PR expression in ER-positive early Luminal $A$ was a significant independent prognostic factor and the difference of prognosis between PR-positive and PR-negative tumors became evident more than 5 years after surgery, resulting in better prognosis in PR-negative than in Luminal B type [16].

According to the 2015 St. Gallen guidelines, both PR and Ki-67 need to be favorable to classify ER-positive breast low risk. ER-positive tumors with low or no PR expression or with high Ki-67 expression are considered high risk and worse survival. Prat et al. also showed that Luminal A tumors with low PR expression carry a poor prognosis [24]. Some of the studies showed a stronger prognostic value of $P R$ status in early Luminal B than early Luminal A type [14], in contrast others found a more substantial impact of $P R$ in low or intermediate proliferating tumors [16]. There are studies for PR expression's prognostic role in different subsets of breast cancer [29], but still limited data on its role in highly proliferating tumors.

Our study was contrary with all of these findings, namely, although survival curves differed between different PR expression either in early Luminal A or early Luminal B, (Figures 3 and 4) and there was evident more significant impact of PR positivity for OS in early Luminal $B$, there was no statistical significance between them ( $p=0.25740, p=0.62294)$ and did not confirm the prognostic effect of PR status and for high proliferative tumors. The explanation of these differences might be because of the different cutoff of $\mathrm{Ki}-67$ and PR among studies, or the small number of patients with Luminal $A$ with low or without PR expression in our study. On the other hand, study of Bardou et al. showed a prognostic and predictive significance of $\mathrm{PR}$ in early stage breast cancer in untreated patients with little effect [10]. However, among patients treated with endocrine therapy, multivariate analyzes (including lymph node involvement, tumor size, and age) showed that PR status was independently associated with OS reducing relative mortality risk of $30 \%$ or $38 \%$, respectively, with ER - negative/PR - negative patients [30].

Patients with ER-positive/PR-negative, ER-negative/PR-positive, and ER-negative/PR-negative tumors have a higher risk of mortality than patients with ER-positive/PR-positive tumors regardless of the demographic and clinical characteristics of the cancer [28].

When we analyzed survival curves for early Luminal $A$ and early Luminal $B$ compared with their advanced stage when both of the receptors were $>1 \%$ (Figures S2 and S3), expression $>1 \%$ of both ER and PR was more protective in early Luminal $B(p=0.00043)$ than it advanced stage, and confirmed the prognostic significance for OS of positive expression of both receptors in early Luminal $B$, but not in early Luminal $A$. 
The subgroup of ER-positive/PR-negative breast cancer showed a prognosis more similar to that of hormone negative breast cancer than to ER-positive/ PR-positive, and had the worse clinical behavior [31].

ER-positive Luminal B type with no PR expression did not show difference of OS between stages ( $p=0.25905)$, so according to this study results the OS in ER-positive early Luminal B type without PR expression could not be predicted without other biological/clinical factors.

Women with ER-positive/PR-negative or ER-negative/PR-positive early Luminal A tumors experienced a higher risk of mortality compared with women with ER-positive/PR-positive tumors [28]. We could not analyze the effect of $E R>1 \% / P R<1 \%$ for OS in early Luminal $A$ because of small number of patients.

Analyzing survival curves in ER-positive early luminal B type with and without PR expression (Figure S5), we did not find PR as an independent prognostic factor for OS $(p=0.23540)$ in highly proliferative early luminal breast cancer.

There are a small number of studies aimed at the subgroup of patients with ER-negative and PR-positive breast cancers due to the small number of respondents and because they are rare type, [28] but they showed that ER-negative/PR-positive subtype of breast cancer was associated with a worse prognosis [32]. This suggests that the assessment of PR expression in tumors with negative ER to identify those who may still benefit from endocrine therapy may not be warranted.

We could not analyze the effect of lacking of ER for OS of early luminal breast cancer, because in early Luminal $A$ there were no patients with $E R<1 \%$ and in early Luminal B there were only 2 patients.

Viale et al., with univariate analysis, confirmed that $\mathrm{Ki}-67$ over $11 \%$ had an inverse association as a prognostic factor [33], [34]. When we analyzed survival curves between different subgroups for a proliferative index of early Luminal B breast cancer, there was clinically evident better survival for $>14-20 \%$ subgroup during the evaluation period compared with others, but the difference was no statistically significant ( $p=0.37165)$. We did not prove the Ki-67 status of early Luminal B as an independent prognostic factor for OS.

Namely, there is still little doubt about the prognostic information of $\mathrm{Ki}-67$ [12], and the predictive value of high values for the introduction of chemotherapy [35]. Studies have limitations in terms of a small number of patients, different inclusion criteria, the study design, $\mathrm{Ki}-67$ analysis methods, and $\mathrm{Ki}-67$ cross-sectional value. In the multivariate model, Ki-67 proved to be an independent parameter for DFS and OS about to other histopathological parameters, where the values above $15 \%$ had a linear correlation with OS which proved its prognostic value [34], [36]. What remains to be debated, however, is the cross-sectional value of Ki-67. On the other hand, study of Ferguson et al. showed that
Ki-67 had statistical significance on the ER/PR/HER2 subtypes, but cannot predict survival [37].

When we analyzed survival curves in univariate analysis for OS of early Luminal A type, ER expression showed protective impact for OS so it was an independent prognostic factor. (Exp [B] [HR] 0.010) However, in the early Luminal $B$ type no biological factor (ER, PR, and Ki-67) was independent factors for OS.

This study's results have clinical significance for the prediction of OS in early luminal breast cancers based on IHC findings for ER, PR, and Ki-67 when genetic testing is not available.

The limitation of the study is its retrospective design and the small number of enrolled patients with early Luminal $A$, which resulted in small number of patients with different combinations of ER and PR expression.

\section{Conclusion}

Our results showed that early luminal breast cancers were not predictive for ER's expression status. Early Luminal B was predictive for PR expression, but not for Ki-67. In terms of OS, ER was an independent prognostic factor only for early Luminal A. PR expression did not show its independent prognostic value besides other pathological features neither of early Luminal $A$ nor early Luminal B breast cancer. Proliferative index $\mathrm{Ki}-67$ was not an independent prognostic factor for OS of highly proliferative early breast cancer.

\section{References}

1. Ferlay J, Steliarova-Foucher E, Lortet-Tieulent J, Rosso S, Coebergh JW, Comber $\mathrm{H}$, et al. Cancer incidence and mortality patterns in Europe: Estimates for 40 countries in 2012. Eur J Cancer. 2013;49(6):1374-403. https://doi.org/10.1016/j. ejca.2012.12.027

PMid:23485231

2. Gamucci T, Vaccaro A, Ciancola F, Pizzuti L, Sperduti I, Moscetti L, et al. Recurrence risk in small, node-negative, early breast cancer: A multicenter retrospective analysis. J Cancer Res Clin Oncol. 2013;139(5):853-60. https://doi.org/10.1007/ s00432-013-1388-2

PMid:23411686

3. Gnant M, Thomssen C, Harbeck N. St. Gallen/Vienna 2015 A brief summary of the consensus discussion. Breast Care. 2015;10(2):124-30. https://doi.org/10.1159/000430488 PMid:26195941

4. Effi AB, Aman NA, Koui BS, Koffi KD, Traore ZC, Kouyate M. Breast cancer molecular subtypes defined by ER/PR and HER2 status: Association with clinicopathologic parameters in ivorian patients. Asian Pac J Cancer Prev. 2016;17(4):1973-8. https:// doi.org/10.7314/apjcp.2016.17.4.1973 


\section{PMid:27221883}

5. Park C, Park K, Kim J, Sin Y, Park I, Cho H, et al. Prognostic values of negative estrogen or progesterone receptor expression in patients with luminal B HER2-negative breast cancer. World J Surg Oncol. 2016;14(1):244. https://doi.org/10.1186/ s12957-016-0999-x

PMid:27619909

6. Cheang MC, Chia SK, Voduc D, Gao D, Leung S, Snider J, et al Ki67 index, HER2 status, and prognosis of patients with luminal B breast cancer. J Natl Cancer Inst. 2009;101(10):736-50. https://doi.org/10.1093/jnci/djp082

PMid:19436038

7. Mojarad S, Venturni B, Fulgenzi, Papaleo R, Brisgotti M, Monti F. Prediction of nodal metastasis and prognosis of breast cancer by ANN-based assessment of tumour size and p53, Ki-67 and steroid receptor expression. Anticancer Res. 2013;33(9):3925-33.

PMid:24023330

8. Murphy LC, Watson P. Steroid receptors in human breast tumorigenesis and breast cancer progression. Biomed Pharmacother. 2002;56(2):65-77. https://doi.org/10.1016/ s0753-3322(01)00157-3

PMid: 12000137

9. Cui X, Schiff R, Arpino G, Osborne K, Lee A. Biology of progesterone receptor loss in breast cancer and its implications for endocrine therapy. J Clin Oncol. 2005;23(30):7721-35. https://doi.org/10.1200/jco.2005.09.004 PMid:16234531

10. Bardou VJ, Arpino G, Elledge RM, Osborne CK, Clark GM. Progesterone receptor status significantly improves outcome prediction over estrogen receptor status alone for adjuvant endocrine therapy in two large breast cancer databases. J Clin Oncol. 2003;21(10):1973-9. https://doi.org/10.1200/ jco.2003.09.099

PMid:12743151

11. Inic Z, Zegarac M, Inic M, Markovic I, Kozomara Z, Djurisic I, et al. Difference between luminal A and luminal B subtypes according to $\mathrm{Ki}-67$, tumor size, and progesterone receptor negativity providing prognostic information. Clin Med Insights Oncol. 2014;8:107-11. https://doi.org/10.4137/cmo.s18006 PMid:25249766

12. de Azambuja E, Cardoso F, de Castro G J, Colozza M, Mano MS, Durbecq V, et al. Ki-67 as prognostic marker in early breast cancer: A meta-analysis of published studies involving 12155 patients. Br J Cancer. 2007;96(10):1504-13. https://doi. org/10.1038/sj.bjc. 6603756

PMid: 17453008

13. Urruticoechea A, Smith IE, Dowsett M. Proliferation marker Ki-67 in early breast cancer. J Clin Oncol. 2005;23:7212-20. https://doi.org/10.1200/jco.2005.07.501 PMid:16192605

14. Van Asten K, Slembrouck L, Olbrecht S, Jongen L, Brouckaert O, Wildiers $\mathrm{H}$, et al. Prognostic value of the progesterone receptor by subtype in patients with estrogen receptorpositive, HER-2 negative breast cancer. Oncologist. 2019;24(2):165-71. https:// doi.org/10.1634/theoncologist.2018-0176

PMid:30171067

15. Pérez-López M, García-Gómez J, Alves M, Paradela A, García-Mata J, García-Caballero T. Ki-67 is a prognostic marker for hormone receptor positive tumors. Clin Trans Oncol. 2016;18(10):996-1002. https://doi.org/10.1007/ s12094-015-1472-y PMid:26742937

16. Ono M, Tsuda H, Yoshida M, Shimizu C, Kinoshita T, Tamura K. Prognostic significance of progesterone receptor expression in estrogen-receptor positive, HER2-negative, node-negative invasive breast cancer with a low Ki-67 labeling index. Clin Breast Cancer. 2017;17(1):41-7. https://doi.org/10.1016/j. clbc.2016.06.012

PMid:27477822

17. Sinna HP, Kreipeb H. A brief overview of the WHO classification of breast tumors, $4^{\text {th }}$ edition, focusing on issues and updates from the $3^{\text {rd }}$ edition. Breast Care. 2013;8(2):149-54. https://doi. org/10.1159/000350774

\section{PMid:24415964}

18. Weiss A, King T, Hunt K, Mittendorf E. Incorporating biologic factors into the American joint committee on cancer breast cancer staging system: Review of the supporting evidence. Surg Clin North Am. 2018;98(4):687-702. https://doi.org/10.1016/j. suc.2018.03.005

PMid:30005768

19. Allison K, Hammond E, Dowsett M, McKernin S, Carey L, Fitzgibbons $\mathrm{P}$, et al. Estrogen and progesterone receptor testing in breast cancer: ASCO/CAP guideline update. J Clin Oncol. 2020;38(12):1346-66. https://doi.org/10.1200/jco.19.02309 PMid:31928404

20. Coates AS, Winer EP, Goldhirsch A, Gelber RD, Gnant M, Piccart-Gebhart $M$, et al. Tailoring therapies--improving the management of early breast cancer: St Gallen international expert consensus on the primary therapy of early breast cancer 2015. Ann Oncol. 2015;26:1533-46. https://doi.org/10.1016/j. breast.2003.09.007

PMid:25939896

21. Harbeck N, Thomssen C, Gnantc M. St. Gallen 2013: Brief preliminary summary of the consensus discussion. Breast Care. 2013;8(2):102-9. https://doi.org/10.1159/000351193

PMid:24000280

22. Nowikiewicz $\mathrm{T}$, Chmielowska $\mathrm{E}$, Andrusewicz $\mathrm{H}$ Łysik-Miśkurka J, Głowacka I, Sowa M, et al. Prevalence of biological types of breast cancer and their influence on disease staging and therapeutic management a single-center study. Pol J Pathol. 2017;68(1):16-25. https://doi.org/10.5114/ pjp.2017.67611

PMid:28547976

23. Cherbal F, Gaceb H, Mehemmai C, Saiah I, Bakour R, Rouis A, et al. Distribution of molecular breast cancer subtypes among Algerian women and correlation with clinical and tumor characteristics: A population-based study. Breast Dis. 2015;35(2):95-102. https://doi.org/10.3233/bd-150398 PMid:25736840

24. Prat A, Cheang M, Martín M, Parker J, Carrasco E, Caballero R, et al. Prognostic significance of progesterone receptor-positive tumor cells within immunohistochemically defined luminal a breast cancer. J Clin Oncol. 2013;31(2):203-9. https://doi. org/10.1200/jco.2012.43.4134 PMid:23233704

25. Sturat-Harris R, Caldas C, Pinder E, Pharoah P. Proliferation markers and survival in early breast cancer: A systematic review and meta-analysis of 85 studies in 32,825 patients. Breast. 2008;17(4):323-34. https://doi.org/10.1016/j. breast.2008.02.002

PMid: 18455396

26. Polley MY, Leung S, McShane L, Gao D, Hugh J, Mastropasqua $\mathrm{M}$, et al. An international Ki67 reproducibility study. J Natl Cancer Inst. 2013;105(24):1897-906. PMid:24203987

27. Bravaccini S, Bronte G, Scarpi E, Ravaioli S, Maltoni R, Mangia $A$. The impact of progesterone receptor expression on prognosis of patients with rapidly proliferating, hormone receptor-positive early breast cancer: A post $\mathrm{HOC}$ analysis of the 
IBIS 3 trial. Ther Adv Med Oncol. 2020;12:1758835919888999. https://doi.org/10.1177/1758835919888999

PMid:32158505

28. Purdie CA, Quinlan P, Jordan LB, Ashfield A, Ogston S, Dewar JA, et al. Progesterone receptor expression is an independent prognostic variable in early breast cancer: A population-based study. Br J Cancer. 2014;110(3):565-72. PMid:24300977

29. Simone G, Diotaiuti S, Digennaro M, Sambiasi D, De Summa S, Tommasi S, et al. Comment on renewed interest in the progesterone receptor in breast cancer. $\mathrm{Br} \mathrm{J}$ Cancer. 2017;117(2):e1. https://doi.org/10.1038/bjc.2017.90 PMid:28399113

30. Nordenskjöld A, Fohlin H, Fornander T, Löfdahl B, Skoog L, Stål $\mathrm{O}$. Progesterone receptor positivity is a predictor of long-term benefit from adjuvant tamoxifen treatment of estrogen receptor positive breast cancer. Breast Cancer Res Treat. 2016;160(2):313-22. https://doi.org/10.1007/ s10549-016-4007-5

PMid:27722840

31. Creighton CJ, Osborne C, van de Vijver MJ, Foekens JA, Klijn JG, Horlings HM, et al. Molecular profiles of progesterone receptor loss in human breast tumors. Breast Cancer Res Treat 2009;114(2):287-99. https://doi.org/10.1007/ s10549-008-0017-2

PMid:18425577

32. Mohsin S, Weiss H, Havighurst T, Clark G, Berardo M, Roanh le D, et al. Progesterone receptor by immunohistochemistry and clinical outcome in breast cancer: A validation study. Mod Pathol. 2004;17(12):1545-54. https://doi.org/10.1038/ modpathol.3800229

PMid: 15272277
33. Inwald EC, Klinkhammer-Schalke M, Hofstädter F, Zeman F, Koller M, Gerstenhauer M, et al. Ki-67 is a prognostic parameter in breast cancer patients: results of a large population-based cohort of a cancer registry. Breast Cancer Res Treat. 2013;139(2):53952. https://doi.org/10.1007/s10549-013-2560-8 PMid:23674192

34. Viale G, Giobbie-Hurder A, Regan MM, Coates AS Mastropasqua MG, Dell'Orto $\mathrm{P}$, et al. Prognostic and predictive value of centrally reviewed Ki-67 labeling index in postmenopausal women with endocrine-responsive breast cancer: Results from Breast International Group Trial 1-98 comparing adjuvant tamoxifen with letrozole. J Clin Oncol. 2008;26(34):5569-75. https://doi.org/10.1200/jco.2008.17.0829 PMid: 18981464

35. Criscitiello C, Disalvatore D, De Laurentiis M, Gelao L, Fumagalli L, Locatelli M, et al. High Ki-67 score is indicative of a greater benefit from adjuvant chemotherapy when added to endocrine therapy in luminal B HER2 negative and nodepositive breast cancer. Breast. 2014;23(1):69-75. https://doi. org/10.1016/j.breast.2013.11.007

PMid:24314620

36. Parise A, Caggiano V. Breast cancer survival defined by the ER/PR/HER2 subtypes and a surrogate classification according to tumor grade and immunohistochemical biomarkers. J Cancer Epidemiol. 2014;2014:469251. https://doi. org/10.1155/2014/469251

PMid:24955090

37. Ferguson NL, Bell J, Heidel R, Lee S, Vanmeter S, Duncan L, et al. Prognostic value of breast cancer subtypes, Ki-67 proliferation index, age, and pathologic tumor characteristics on breast cancer survival in Caucasian women. Breast J. 2013;19(1):22-30. https://doi.org/10.1111/tbj.12059

PMid:23240985 


\section{Supplementary}

Table S1: Prevalence of biological types of breast cancer from immunohistochemical findings

\begin{tabular}{lll}
\hline Biological type & $\mathrm{N}$ & $\%$ \\
\hline Luminal A & 54 & $16.1 \%$ \\
Luminal B & 200 & $5.5 \%$ \\
Triple negative & 33 & $9.8 \%$ \\
HER2/neu positive & 49 & $14.6 \%$ \\
TOTAL & 336 & $0 \%$ \\
\hline
\end{tabular}

Table S2: Prevalence of Luminal A and Luminal B / early and advanced breast cancer

\begin{tabular}{lllllll}
\hline \multirow{2}{*}{ Cancer stage } & \multicolumn{1}{l}{ Luminal A } & \multicolumn{2}{l}{ Luminal B } & \multicolumn{2}{l}{ Luminal A+B } \\
\cline { 2 - 7 } Early & $\mathrm{N}$ & $\%$ & $\mathrm{~N}$ & $\%$ & $\mathrm{~N}=336$ & $\%$ \\
Advanced & 41 & $75.9 \%$ & 126 & $63 \%$ & 167 & $49.7 \%$ \\
TOTAL & 13 & $24.1 \%$ & 74 & $37 \%$ & 87 & $25.9 \%$ \\
& 54 & $0 \%$ & 200 & $100 \%$ & & \\
& Pearson Chi-square $=83502 ; \mathrm{p}=0.0001^{*}$.
\end{tabular}

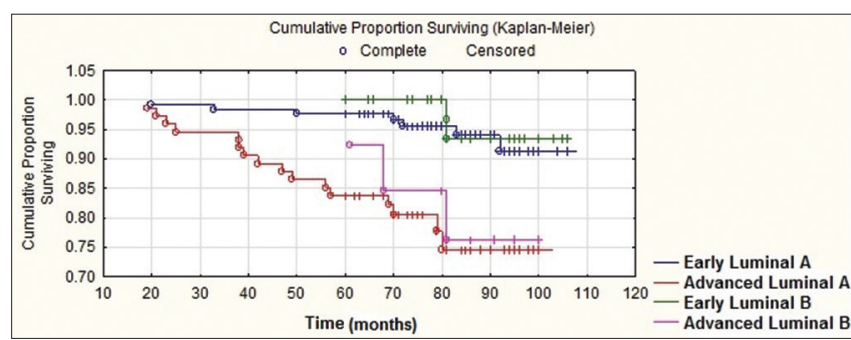

Figure S1: Kaplan-Meier survival curves for overall survival of 254 patients stratified according to Luminal A and Luminal B breast cancer

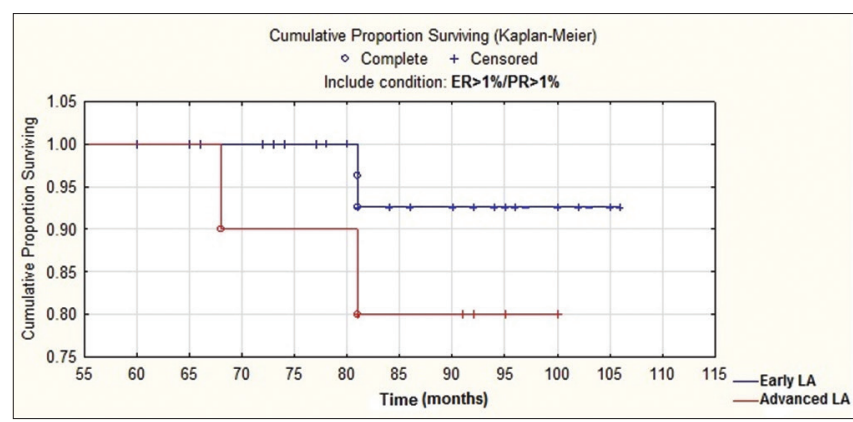

Figure S2: Survival curve for overall survival of patients with early Luminal A breast cancer with $E R>1 \% / P R>1 \%$

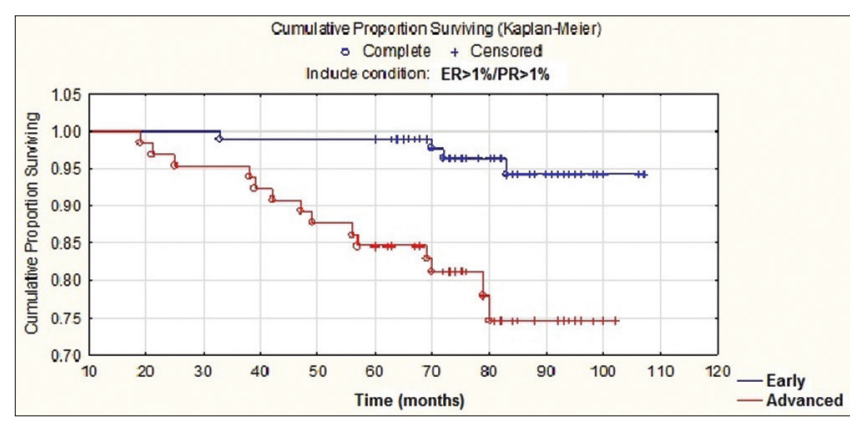

Figure S3: Survival curve for overall survival of patients with early Luminal $A$ and Luminal $B$ breast cancer with $E R>1 \% / P R>1 \%$

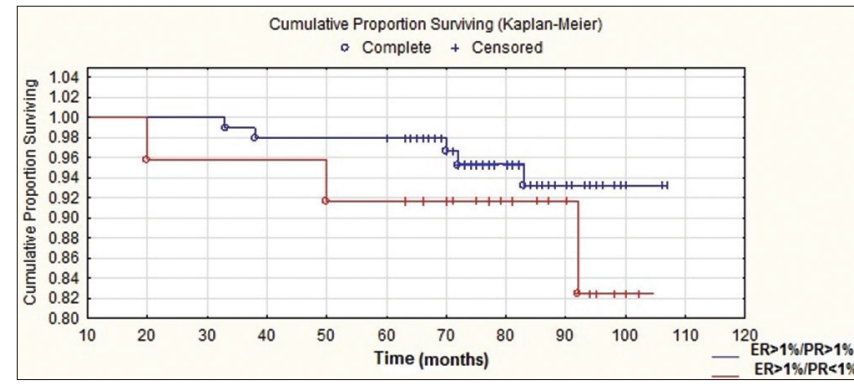

Figure S4: Survival curve for overall survival of patients with early Luminal $B$ breast cancer with $E R>1 \% / P R<1 \%$

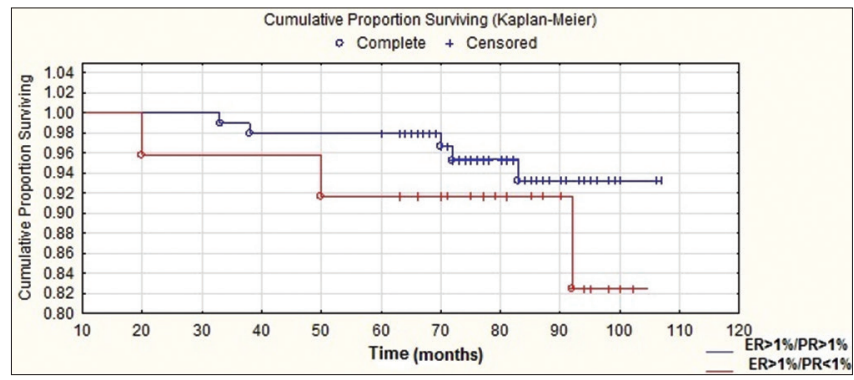

Figure S5: Comparison of overall survival curves between ER>1\%/ $P R>1 \%$ and $E R>1 \% / P R<1 \%$ early Luminal $B$ breast cancer 